\title{
A Formação Acadêmica e a Ciência: Ampliando o Debate sobre o Mestrado Profissional
}

Peter Spink

O professor Pedro Lincoln Mattos (Mattos, 1997) defende bem seu argumento de que tanto as boas dissertações acadêmicas como as boas dissertações de mestrado profissional cabem no conceito de pós-graduação stricto sensu. Se a ciência é "um discurso crítico, movido pela fé na possibilidade humana do acerto", e suas condições são a clareza do objeto do discurso, sua consistência, transparência e abertura de método, "para que outros possam também percorrer tal caminho e discuti-lo", segue que não é o que alguém é ou onde está que define a atividade, mas sim a sinceridade em assumi-la enquanto proposta intersubjetiva de ação numa comunidade moral (Selznick, 1992).

Se aceitar que cientistas determinam o que é ciência já é perigoso, especialmente dadas as suas fronteiras compartilhadas com o senso comum e com a ideologia (Gouldner, 1976), permitir que somente certos cientistas determinem o que é um cientista é o caminho mais curto para um discurso truncado e não crítico, movido pela hegemonia e pela tentação de dominação sistêmica (Habermas, 1984). Feyerabend (1975, p.12) analisou bem este problema da definição da atividade científica no seu livro Contra o Método e na sua proposição de rodapé, acerca da importância de assumir uma postura dadaísta:

"A Dadaist would not hurt a fly - let alone a human being. A Dadaist is utterly unimpressed by any serious enterprise and he smells a rat whenever people stop smiling and assume that attitude and those facial expressions which indicate that something important is about to be said. A Dadaist is convinced that a worthwhile life will arise only when we start taking things lightly. [...]. A Dadaist is prepared to initiate joyful experiments even in those domains where change and experimentation seem to be out of the question".

Boa parte das dificuldades em volta do mestrado profissional e de sua dissertação não são oriundas da idéia em si - o texto também deixa isso claro - mas da própria academia brasileira e da forma em que ela se constituiu no seu processo sócio-histórico. Portanto, o problema não é de determinar se um mestrado profissional "é" ou "não é" algo no seu sentido genérico, mas compreender como as construções específicas de mestrado, doutorado, dissertação e tese se formaram enquanto instituições do cotidiano acadêmico. 
Um ponto de partida possível é uma questão que o texto pouco aborda e mesmo assim de forma não problemática: será que o papel da dissertação de mestrado é produzir conhecimento? Do ponto de vista formal, a resposta a esta indagação é simples: não. A grande maioria de dissertações tem na sua contracapa a expressão "apresentado como parte dos requisitos para obtenção de [...]", ou algo similar. Assim sendo, o mestrado é um exercício estruturado de aprendizagem, em que o fazer é ao mesmo tempo aprender e a avaliação do resultado final verifica se isso foi satisfatoriamente feito de acordo com o julgamento de pessoas com mais experiência. Atividades parecidas podem ser encontradas nas mais variadas profissões: elas ajudam a fixar o "saber como" e o "saber por que" de um campo de conhecimento. Não é esperado que produzam conhecimento e isso não é um requisito nem um objetivo. Entretanto, se acontece, o aprendiz não vai ser punido e pode até ser congratulado.

Se uma dissertação é essencialmente um processo de aprendizagem, de início, meio e fim - incluindo, entre outros, o porque da questão escolhida, o aprender a receber críticas, a ética da investigação e a sinceridade na dúvida - segue-se que uma dissertação num curso de mestrado voltado à interpretação da prática, à discussão de idéias, conceitos e teorias, e ao delineamento de linhas de ação a partir do conhecimento, deve contribuir para este objetivo, tanto em termos de instrumento de aprendizagem quanto em termos de mecanismo de avaliação.

Conseqüentemente, não há nenhuma razão para que uma dissertação em um mestrado dito profissional seja diferente - em termos substantivos - de qualquer outra dissertação. Pode ser diferente em forma e em estilo, pode focalizar certas questões mais que outras, pode incluir e privilegiar diferentes fontes e estratégias de coleção de dados, mas se ajuda a fixar o "saber como" e o "saber por que" e a avaliar a compreensão do candidato sobre seu papel neste "discurso crítico, movido pela fé na possibilidade humana do acerto", será uma dissertação.

Por que, então, tanta polêmica em volta da questão da dissertação do mestrado profissional e por que o uso da palavra "profissional" vem carregado com tantas emoções? Sem dúvida, parte do dilema está na questão de acesso a recursos, de títulos vistos como propriedade, e do medo de compartilhar com o outro, que reflete o drama nacional da redistribuição negativa. Em muitas áreas, títulos acadêmicos não são etapas preparatórias para ingressar numa carreira, mas os elementos da carreira em si, a serem galgados pouco a pouco em direção à aposentadoria. Sendo produtos de uma lógica institucional própria num sistema quasefechado, é inevitável que a sua repentina adoção em outros espaços de forma mais abrangente afetará os mecanismos de reprodução vigentes, seja diretamente pela aparente "desvalorização" que o acesso mais amplo traz, ou indiretamente, pelas questões - já levantadas - sobre o que é ou deve ser, afinal, um mestrado. 
Também parte do dilema está nas falsas separações entre as reflexões da academia e as ações no mundo, entre scholars e practitioners (para usar a distinção comum nos Estados Unidos), ou entre os intelectuais e os artesãos. Não é o momento de aprofundar a sutileza nefasta destas distinções e suas conseqüências nas múltiplas esferas da ação social; suficiente é notar sua fragilidade em face da transformação do conceito de intelectual nas mãos brilhantes de Antonio Gramsci (Hoare e Smith, 1971), ou lembrar a visão de Kurt Lewin (Spink, 1979; Thiollant, 1997) de que não há nada mais prático do que uma boa teoria e a longa e extremamente produtiva tradição de pesquisa-ação que esta expressão gerou.

Esses conteúdos específicos só se fazem presentes à medida que há práticas e oportunidades que permitam que seus significados sejam mobilizados. Não se trata aqui de argüir se no Brasil o campo de ensino e pesquisa das universidades e dos títulos é ou não especificamente minado com as temáticas de reprodução e de luta social. Pelo contrário, cabe lembrar que qualquer campo de ensino e pesquisa das universidades e dos títulos, de qualquer país, será inevitavelmente minado com as temáticas de reprodução e de luta social, presentes não só nas ações de elites, mas também nas dos demais atores institucionais (Bourdieu e Passeron, 1977).

Onde estes temas podem ser encontrados no caso brasileiro e mais precisamente no caso da administração é, paradoxalmente, dentro de uma história de sucesso: a da própria implantação da pós-graduação. Durante muito tempo, e de certa forma, até os dias de hoje, o mestrado foi o título mais presente no cenário acadêmico, e a maioria dos cursos eram e continuam sendo de mestrado. Professores foram enviados para outros países para fazer seus doutorados mas, e de maneira sensata para garantir a variedade em abordagem e postura, sempre distribuídos entres países e universidades. Junto com cada doutorado veio a aprendizagem sobre sua inserção institucional numa teia de significados acadêmicos e sociais próprios, mas estava restrito o espaço para aproveitar esta experiência e criar no debate do dia-a-dia uma nova institucionalidade específica. Os doutorados seriam criados em grande parte após os mestrados. Sem uma prática de doutorado, o mestrado achou seu caminho - sendo definido a partir de uma visão restrita de conhecimento, acesso e uso - e descobriu sua forma. Adquiriu uma importância que leva famílias a assistir às defesas de seus parentes, de uma obrigação de erudição e de argüição que muitas vezes pouco tem a ver com o diálogo e com o revestimento do produto na categoria de conhecimento. É claro que para cada elemento há uma razão ou uma resposta de bom senso - não é isso que está em debate. É simpático assistir ao processo de aprendizagem e de argumentação e fazer parte dele; é bom aprender a se defender em público - e que melhor público para começar do que aquele formado pelos amigos? O importante é a conseqüência: uma construção social própria do mestrado e de sua dissertação que se espelha 
na polêmica sobre sua vertente profissional. Ao olhar-se para dentro das críticas sobre o mestrado profissional, encontra-se o significado mais amplo do modelo anterior.

O eixo em que a luta simbólica parece mais forte é aquele que traz o "sotaque" do conhecimento. De novo isso se coloca de forma contraditória. Usando como indicador o encontro anual da ANPAD, não há dúvida de que, de forma gradativa e constante, se foi construindo uma capacidade efetiva de gerar idéias, práticas e observações pertinentes, ou seja, conhecimento. Acadêmicos em visita ao país ficam surpresos ao encontrar uma vigorosa comunidade que avalia trabalhos sem a identificação dos autores e que chegam a rejeitar duas inscrições para cada uma que é aceita. O preço pago por isso, entretanto, foi o deslocamento do mestrado de sua função como processo de aprendizagem sobre o "saber como" e "saber por que" para o campo da construção do conhecimento. A construção social do mestrado levou seu significado numa direção própria, que precisa ser explicitamente questionada. Com ênfase, de forma sutil, no papel do mestrado enquanto contribuição ao conhecimento, cria-se inevitável conflito, quando se lança a possibilidade não somente de mestrado profissional, mas também a de permitir que o mestrado profissional possa contar com uma dissertação, e que talvez esta venha a ter feições diferentes, sobretudo em um mundo onde a distinção entre teoria e prática não somente existe, mas, pior, é revestida com significados de superioridade. Ao trazer o mestrado profissional para o cenário de títulos acadêmicos, torna-se evidente a falta de discussão substantiva não sobre o mestrado profissional, mas sobre o mestrado em si, não sobre sua dissertação mas sobre a dissertação do modelo atual. Afinal, para que serve a dissertação? E, além disso, como avaliar uma boa dissertação, seja ela acadêmica, profissional, acadêmico-profissional ou simplesmente uma dissertação de mestrado?

Em muitos países esta temática é tornada pragmaticamente mais fácil pela presença no cotidiano institucional acadêmico de diversos graus e opções de forma simultânea. É claro que não emergiram assim, mas sua presença conjunta é assumida dentro do horizonte atual. Conseqüentemente, de país para país, mestrados, doutorados, livres-docências e outros exercícios de aptidão e aprendizagem formam conjuntos específicos que dividem o espaço de formação e se complementam e se restringem mutuamente. Quando um professor no Reino Unido observa para seu orientando que seu trabalho extrapola as necessidades de um mestrado e que o candidato deve optar por fazer algo mais simples ou pedir a transferência diretamente para o doutorado, ele o faz a partir do senso socialmente compartilhado e construído dos limites entre um e outro. Até mesmo o doutorado, sempre visto como teste de capacidade de produzir algo original, também em muitos lugares começa a adquirir uma característica opcional. Os britânicos, por exemplo encorajam seus jovens e mais brilhantes cientistas de laboratório das áreas exatas a 
não gastar tempo com titulação e partir direto para a publicação. A razão não é somente o valor relativo entre um artigo em Nature e um doutorado da Universidade de Londres, mas é também a presença institucional do $D S c$ ou Doutorado de Ciência, de nível mais elevado do que o $P h D$, que requer o depósito de toda a produção acadêmica do candidato por um período de, no mínimo, cinco anos (normalmente é muito mais) para ser posteriormente avaliada por uma banca. Não é uma questão de saber se o modelo britânico é correto ou não (ele é tão contraditório quanto qualquer outro), nem se é apropriado para outros países. O importante é que tem sentido para eles e permite que tomem decisões, conversem, formem gente e eventualmente produzam conhecimento. Também serve de terreno de significados que podem ser e são anexados por fins diversos: para afastar críticas e proteger interesses, criar carreiras e organizações, garantir privilégios e reproduzir classes. Sendo produto social, se expande e se altera no decorrer dos eventos. Um modelo nunca é estático e, de novo no caso britânico, pode se anotar a introdução relativamente recente (30 anos) da distinção entre mestrados com dissertação e mestrados por exame final.

Sem correr o risco de trocar um argumento por outro, a ausência de uma sólida tradição com o doutorado sem dúvida torna difícil a construção de uma identidade para um mestrado enquanto prática cotidiana e parte de uma ecologia institucional de opções e progressões. Não se trata de ter o doutorado eventualmente neste ou naquele lugar do país ou mesmo de se ter acesso ao doutorado em outros países; o importante é sua presença no cotidiano da vida universitária, forçando candidatos e professores a refletir abertamente, dentro do processo de orientação, sobre demandas, exigências e suas relativas dimensões. Pode ser que o resultado desta reflexão seja que o nosso mestrado deva, de fato, requerer a aprendizagem e a produção de conhecimento original, e que conseqüentemente o nosso doutorado deve ser algo parecido com a inscrição para o Prêmio Nobel! É duvidoso que isso aconteça, mas vai depender em parte da forma como andem os processos sociais implicados no acesso à produção e no direcionamento do conhecimento. É muito provável que a introdução do mestrado profissional tivesse sido menos traumática se a questão do mestrado dentro de uma ecologia institucional de títulos tivesse sido parcialmente - porque nunca o será de forma total - resolvida. A associação exagerada do mestrado com o conhecimento e o mundo da academia tornou sua abertura para o mundo "profissional" um pesadelo simbólico, em que todos os esqueletos saíram do armário.

Difícil, entretanto, não quer dizer impossível. E este é o desafio levantado pela ampliação potencial do acesso ao título de mestre e pela ampliação potencial - e porque não também o aprofundamento - da natureza da dissertação enquanto espaço privilegiado de aprendizagem sobre a dilema dos saberes. O desafio é o de assumir a temática da "era dos direitos" (Bobbio, 1996) e, apoiado pelas imagens 
de Marcel Duchamp e seus colegas, ter a coragem de dizer: "mas isso também é dissertação de mestrado".

A ciência, como bem apontou Mattos (1997), é fenômeno social e patrimônio coletivo. Um trabalho feito com honestidade, com base na aprendizagem e reflexão, como elo de ligação entre idéias, práticas e possibilidades, tem o direito de ser considerado parte do mundo acadêmico no seu sentido coletivo. É inevitável que por ser elaborado num diálogo que tem um pé (do orientador) na biblioteca invisível da construção do conhecimento e o outro (do orientando) na construção de eventos, o resultado será para alguns um desafio criativo e para outros algo a ser evitado. É muito provável que alguns dirão "mas isso não é uma dissertação", enquanto outros encontrarão novas idéias sobre como descrever eventos e elaborar reflexões. Em novo cenário, enquanto alguns, presos nas narrativas restritivas e reprodutivas anteriores, serão por isso mesmo menos (ou mais?) exigentes, outros serão estimulados a novas concepções sobre ensino, aprendizagem e conhecimento, quebrando limites e buscando novas exigências. Para retornar ao Feyerabend (1975), há espaço para todos, desde que as pessoas sejam minimamente tolerantes umas com as outras. Não se trata de dizer como será esta dissertação, de como será reconhecida e identificada - e aqui vem a divergência com o texto - porque ao assumir o mestrado profissional, enquanto mestrado se assume sua dissertação, enquanto dissertação. A arte após os dadaístas é uma arte diferente, mas não no capítulo que se refere à sua produção - que, diga-se de passagem, pode ser reconhecida mesmo que ninguém a tenha definido - mas propriamente a arte como um todo. É esta a temática dentro da qual o mestrado profissional deve ser compreendido.

A luta, e não há dúvida que é esta, para o direito a uma prática profissional reflexiva, é também a luta para uma prática acadêmica transformadora, no campo empresarial, nas agências públicas, nas entidades não-formais e nas múltiplas organizações da sociedade civil. A ampliação da competência da dissertação é também a ampliação do próprio campo de administração, oferecendo a possibilidade de um enraizamento mais adequado nas questões de hoje e na realização dos sonhos de amanhã ... com humor se chega lá.

\section{ReFERENCIAS BiblográficAs}

BOBBIO, N.

The age of rights. Cambridge :

Polity Press, 1996.
BOURDIEU, P.; PASSERON, J-C. Reproduction in education, society and culture. London : Sage, 1977. 
FEYERABEND, P.

Against method. London : Verso, 1975.

GOULDNER, A.

The dialectic of ideology and technology. New York: Seabury Press, 1976.

HABERMAS, J.

The theory of communicative action. Boston : Beacon Press, 1984. 1.v.

HOARE, Q.; SMITH, G. N. Selections from the prison notebooks of Antonio Gramsci. New York : International Publishers, 1971.

MATTOS, P. L. M.

Dissertações não-acadêmicas em mestrados profissionais : isso é possível? Revista de Administração Contemporânea, v.1, n.2, p.153-171, 1997.

SELZNICK, P.

The moral commonwealth :

social theory and the promisse of community. Berkeley : University of California Press, 1992.

SPINK, P. K.

Pesquisa-ação e a análise de problemas sociais e organizacionais complexos. Psicologia, v.5, n.1, p.31-44, 1979.
THIOLLENT, M.

Pesquisa-ação nas organizações. São Paulo : Atlas, 1997. 